\title{
A FLEXIBLE DIDACTIC PLATFORM FOR THYRISTOR-BASED CIRCUIT TOPOLOGIES
}

\author{
Lucas Koleff ${ }^{1}$, Lucas Araújo ${ }^{1}$, Mário Zambon ${ }^{1}$, Wilson Komatsu ${ }^{1}$, Eduardo Pellini ${ }^{2}$, \\ Lourenço Matakas Junior ${ }^{1}$ \\ ${ }^{1}$ Power Electronics Laboratory of the Escola Politécnica da Universidade de São Paulo (USP), São Paulo - SP, Brazil \\ ${ }^{2}$ Protection and Automation Laboratory of the Escola Politécnica da Universidade de São Paulo (USP), São Paulo - SP, Brazil \\ e-mail: koleff.lucas@gmail.com, lga261@gmail.com,mfelipe.zambon@gmail.com,wilsonk@usp.br, elpellini@usp.br, \\ matakas@pea.usp.br
}

\begin{abstract}
The objective of this article is to present a flexible didactic platform for thyristor-based circuits. When compared to the existing academic and commercial teaching platforms the proposed one is modular and shows more flexibility. Using the same basic thyristor module, several topologies can be built, including solidstate relays, thyristor bridge rectifiers, and others. All development steps are detailed. Examples of teaching applications, such as the operation of a controlled rectifier, are presented to demonstrate the functionality and didactic usage. Experimental results are also included for the presented applications.
\end{abstract}

Keywords - Education, Power electronics, Thyristors.

\section{INTRODUCTION}

The study of line-commutated power converters is included in most undergraduate and graduate power electronics courses and lectures. Therefore, a demand for didactic platforms allowing experimental verification and laboratory exercises using thyristor-based circuits exists.

Most of the didactic platforms are intended for voltage source converters (VSCs) [1], electrical machine drives [2-5] and photovoltaic (PV) systems [6]. Literature review shows that a small number of academic [7] and commercial [8] didactic platforms specialized in thyristor-based circuits is currently found. Unfortunately, they are inflexible regarding the topology, and this is the motivation for developing the platform presented in this work. In the past, a modular power electronics teaching platform was introduced in [9], and the new platform presented in this paper can be considered an updated design.

The current article is an extension of the conference paper presented in [10], including more details on the circuit development, new references and a novel didactic application. Authorization for reusing content from that article has been obtained from the IEEE.

This paper is organized as follows: i) the basic thyristor element is specified and developed, ii) the interconnection flexibility is explored, iii) some examples of didactic applications are presented and iv) conclusions are given.

Manuscript received 03/18/2020; first revision 04/16/2020; accepted for publication $05 / 08 / 2020$, by recommendation of Editor Demercil de Souza Oliveira Jr.. http://dx.doi.org/10.18618/REP.2020.2.0012

\section{DEVELOPMENT OF THE MODULE}

The basic thyristor module shown in Figure 1 is the main component of the modular platform, featuring a single thyristor and its galvanically isolated gating circuit. By interconnecting several modules, it is possible to study different circuit topologies.

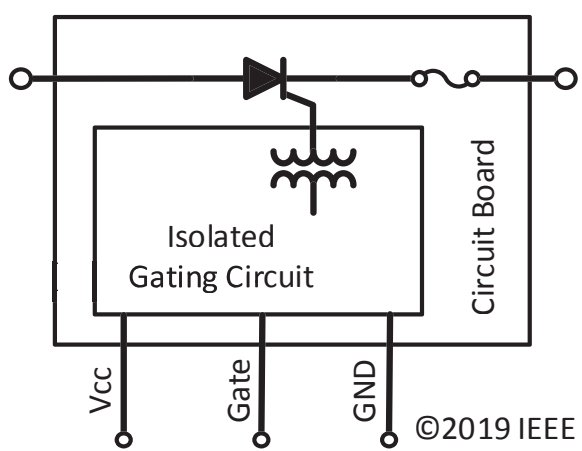

Fig.1. Basic thyristor module of the proposed platform.

\section{A. Specifications}

The thyristor must withstand the peak voltage of the grid considering a reasonable safety margin, as the didactic platform is intended to operate connected to the $\mathrm{AC}$ mains of the laboratory. The current rating of the thyristor is specified to be of 7 A (RMS), which is considered as being enough for most didactic laboratory experiments.

Therefore, the TIC126N thyristor [11] is selected, as it supports a continuous current of 12 A (RMS) and a peak reverse voltage of $800 \mathrm{~V}$. Also, this component is available at low cost at the local market.

When operating at the specified current rating, the power losses at the semiconductor are of $7.7 \mathrm{~W}$. Therefore, an aluminum heatsink is used to provide enough heat dissipation from the thyristor, ensuring that the junction temperature is within acceptable limits.

For designing the printed circuit board (PCB) routing, the IPC-2221 standard [12] is considered. Their widths and clearances are dimensioned for a peak current and a peak voltage of $10 \mathrm{~A}$ and $850 \mathrm{~V}$, respectively. A cartridge fuse according to the IEC 60127-2 standard [13] is used to provide protection against overcurrents.

\section{B. Gating Circuit of the Thyristor Module}

The isolated gating circuit [14] is presented in Figure 2. A MTPT17 pulse transformer [15] ensures galvanic isolation between the control and the power circuit. 


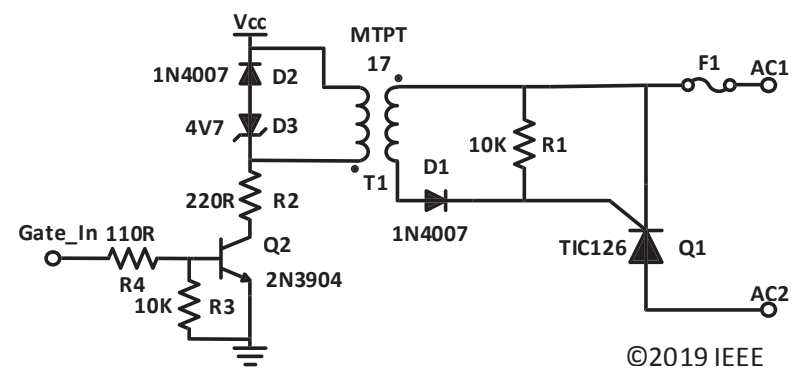

Fig. 2. Circuit diagram of the gating circuit.

The magnetic characteristics of the pulse transformer are determined applying a square-wave excitation on the primary side and acquiring the resulting voltage and current waveforms using an oscilloscope. By integrating the acquired voltage to calculate the concatenated flux, the saturation curve presented in Figure 3 is obtained.

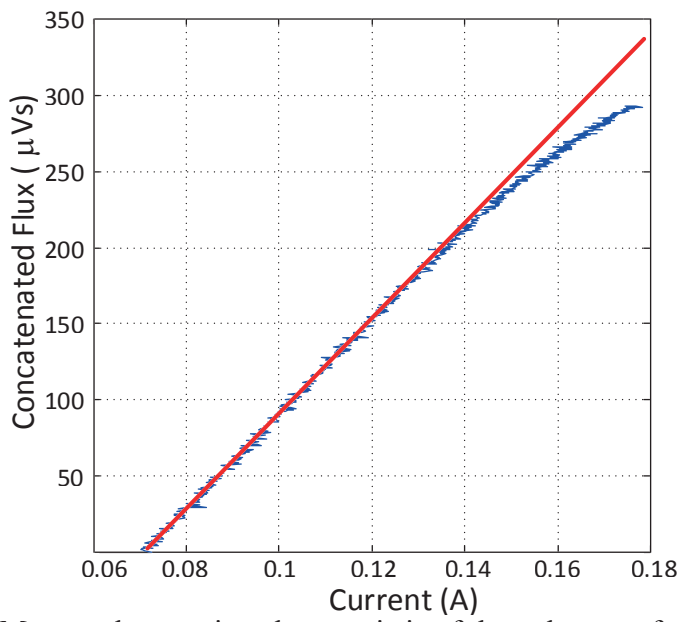

Fig. 3. Measured saturation characteristic of the pulse transformer.

The voltage-time integral of the MTPT17 is determined to be of $250 \mu \mathrm{Vs}$. The nominal gate trigger current of the TIC126N is of $5 \mathrm{~mA}$. In the module, the supply voltage is of $5 \mathrm{~V}$. Therefore, a reasonable gate current margin needs to be considered, guaranteeing the successful firing of the thyristor in every cycle. Under those conditions, the thyristor can be fired using a pulse train with a maximum frequency of 10 $\mathrm{kHz}$ (considering a duty cycle of $50 \%$, resulting in a turn-on pulse length of $50 \mu \mathrm{s}$ ) with a reasonable margin. In Figure 4, the final PCB of the module with populated components is shown.

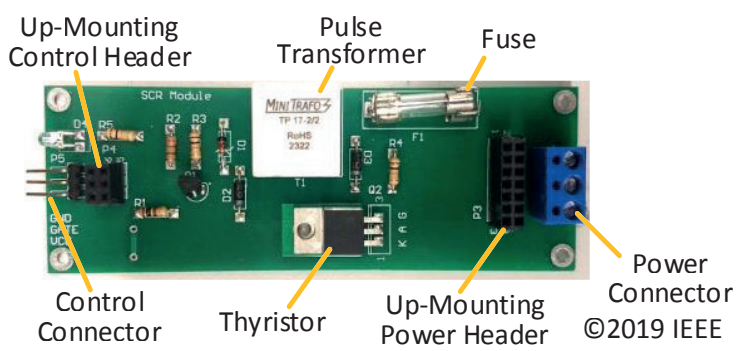

Fig. 4. Picture of the finished Thyristor Module without heatsink.

The up-mounting control and power interconnection headers are highlighted. They are designed to allow mounting two modules, one on top of the other. In that way, the thyristor switches can be connected in anti-parallel to be used as a solid-state relay (SSR).

\section{INTERCONNECTION FLEXIBILITY}

In this section, the three most important interconnection possibilities are introduced.

\section{A. Stand-Alone Thyristor}

The simplest possibility is the stand-alone thyristor, or silicon-controller rectifier (SCR). It is presented in Figure 5, and only one module is used. Its applications include the measurement and determination of the thyristor characteristics (e.g. the forward voltage drop or the holding current) for didactic purposes. Additionally, waveforms of the thyristor on- and off-switching transients can be obtained.

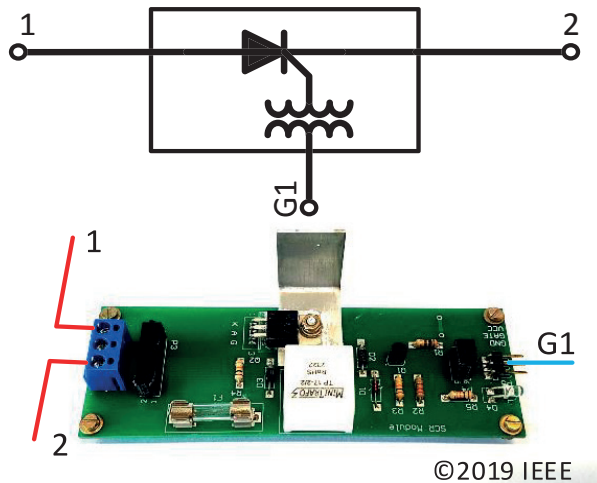

Fig. 5. Silicon controlled rectifier.

\section{B. Solid-State Relay}

Another possibility is to connect two modules on top of each other (anti-parallel connection) to build a bidirectional thyristor switch (or SSR). The anode from the thyristor on the lower module is connected to the cathode from the corresponding thyristor on the upper module and vice-versa using the up-mounting power headers, as shown in Figure 6.
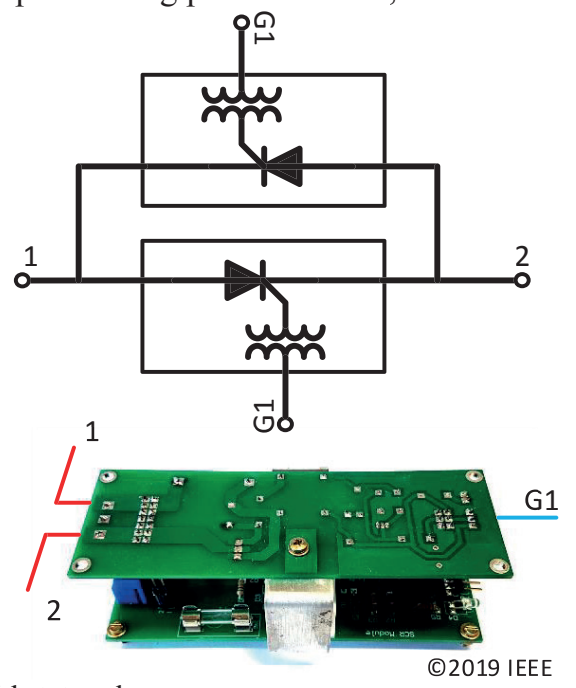

Fig. 6. Solid state relay.

The up-mounting control headers are used to share the power supply of the circuit $\left(\mathrm{V}_{\mathrm{CC}}\right.$ and ground) and the gating signal G1 between the upper and lower modules as well. 
As the SSR can be used to electronically connect or disconnect several types of loads, it is possible to explore several didactic applications. For instance, it can be used in a thyristor-switched capacitor bank for reactive power compensation [16]. In this application, through the SSR, it possible to control the switching instant with higher precision than by using mechanical switches, avoiding current transients that would damage the thyristors.

Other applications of this interconnection are: i) the control of static var compensators (SVCs) [17], through the firing angle variation of a SSR + reactor set; ii) the variation of active power in resistance heating applications by firing angle or integral cycle control of a SSR + resistance set [18]; iii) the limitation of the induction motor inrush current by a soft start strategy (firing angle controls of a SSR + motor set)[19].

\section{Controlled Thyristor Phase-Leg}

By connecting the up-mounting headers in a different configuration, two modules can be series connected to build a single controlled thyristor phase leg, which is shown in Figure 7.
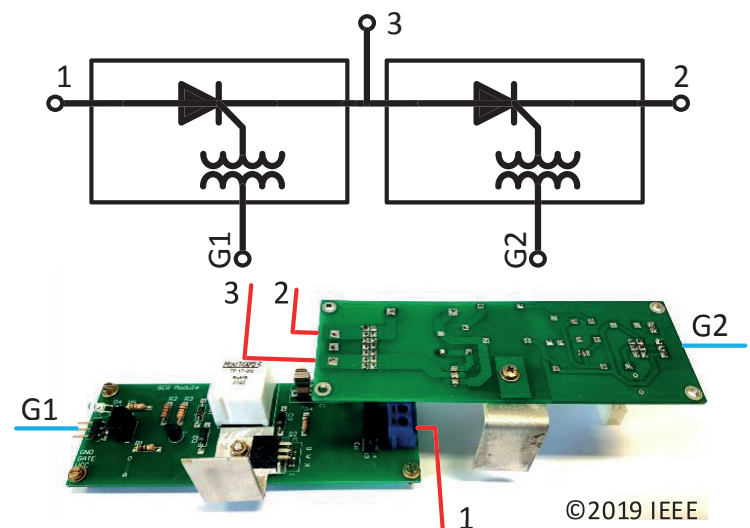

Fig. 7. Controlled thyristor phase-leg.

Usually, several phase-legs are connected in parallel to form a single-phase or a three-phase converter. The range of possible didactic applications is very large and ranges from demonstration of commutations processes in controlled rectifiers to operation of electric machine drives or two quadrant operation.

\section{DIDACTIC APPLICATIONS}

Several didactic applications are presented in this section, including examples of obtained experimental results.

\section{A. Characterization of the Thyristor}

Using the first interconnection possibility, shown in Figure 5, the operating characteristics of the thyristor can be measured. The experimental setup uses a power resistor, a single thyristor module and a DC power supply source, connected as in the circuit diagram shown in Figure 8.

In order to characterize the thyristor, the DC source is set, and the thyristor is in forward blocking mode. The gate pulses are then activated, triggering the device which enters the forward conduction mode. The current and the junction voltage are measured. The source voltage is reduced in several steps, while repeating the measurements. Figure 9 shows the experimental setup and Figure 10 shows the obtained forward conduction characteristic curve.

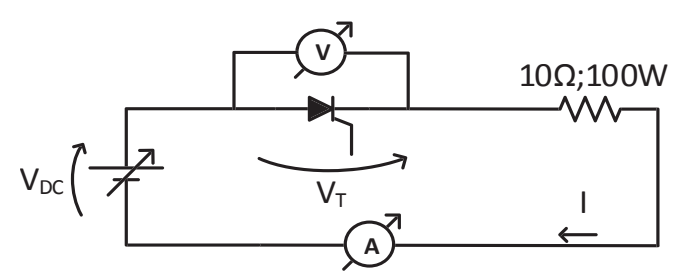

Fig. 8. Circuit diagram of the experimental setup.

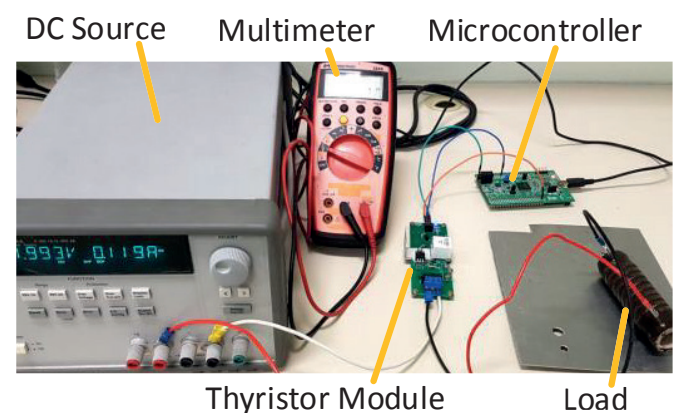

Fig. 9. Test bench for the characterization.

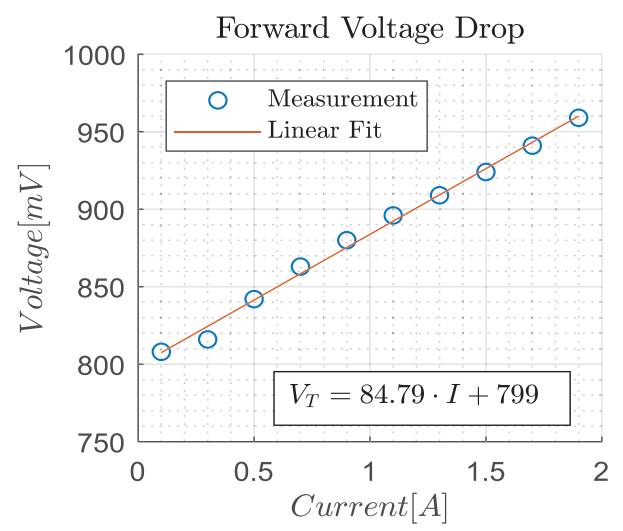

Fig. 10. Forward conduction voltage-current curve of the thyristor.

To measure the holding current of the thyristor, the gate pulses are deactivated after the device is in set in forward conduction mode. The source voltage is reduced until holding current is reached and the thyristor stops conducting. For the TIC126N used in this article, the holding current is measured to be of $30 \mathrm{~mA}$, which is consistent with the expected values. According to the holding current vs. case temperature curve in the datasheet [11], the holding current should be around $25 \mathrm{~mA}$ at a $25^{\circ} \mathrm{C}$ case temperature.

\section{B. Switched Capacitor Bank}

As stated in Section III, the modules can be used in the implementation of a thyristor switched capacitor (TSC) [16]. As shown in Figure 11, the parallel capacitor branches are switched in order to change the amount of reactive power injection performed by the bank.

Next to the circuit diagram of the switched capacitor bank in Figure 11, it is possible to see the variation of the reactive power injection corresponding to the switching states of the bank. The capacitors $C$ are responsible for the reactive power 
injection. The total reactive power injected is defined as $Q$ and the amount provided by each single branch is $Q_{C}$. For simplicity, the switches are represented here by ideal bidirectional switches.
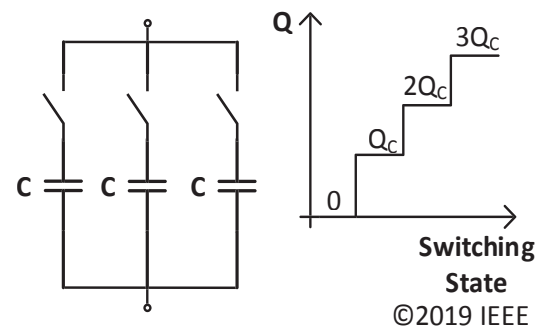

Fig. 11. Principle of operation of a capacitor bank.

For a single switched capacitor branch, the equivalent circuit diagram is shown in Figure 12. The thyristor switches are represented by $\mathrm{S}$, the capacitor voltage by $v_{c}(t)$, the grid voltage by $v(t)$, the capacitor bank input voltage by $v_{A c}(t)$ and the branch current by $i(t)$. The equivalent grid inductance is represented by $L_{S}$ and the equivalent grid resistance by $R_{S}$.

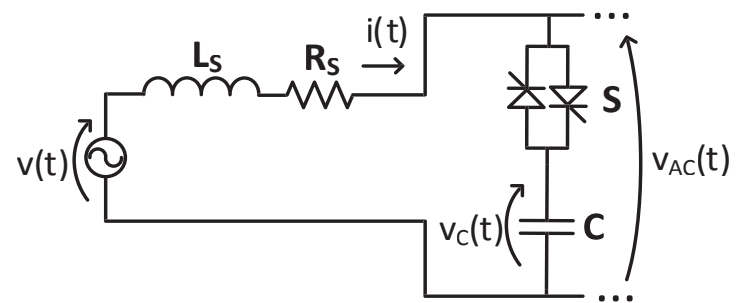

Fig. 12. Equivalent circuit diagram of a switched branch.

In [16] and [17], the usage of a series inductor is recommended in order to limit switching transients. As seen in [20], it is possible to mitigate transient overcurrents by controlling the switching instant precisely using the thyristor switches. If mechanical switches are applied instead, it is not possible to accurately control the switching instant.

When the switching instant is controlled, the optimal instant $t_{s}$ is when the instantaneous capacitor voltage is equal to the bank input voltage (i.e. when the voltage drop on the open switch is zero), as shown in (1).

$$
v_{A C}\left(t_{S}\right)=v_{c}\left(t_{S}\right)
$$

The optimal firing angle $\alpha$ is calculated in (2), where $V_{c 0}$ is the initial voltage across the capacitor terminals and $V$ is the peak voltage of the grid.

$$
\alpha=\sin ^{-1} \frac{V_{c 0}}{V} \text {. }
$$

In Table I, the parameters of the capacitor bank setup are listed.

TABLE I

Circuit Parameters

\begin{tabular}{cc}
\hline Parameter & Value \\
\hline$L_{S}$ & $50 \mu \mathrm{H}$ \\
\hline$C$ & $25 \mu \mathrm{F}$ \\
\hline$R_{S}$ & $0.5 \Omega$ \\
\hline$\omega_{0}$ & $377 \mathrm{rad} / \mathrm{s}$ \\
\hline & (C) $2019 \mathrm{IEEE}$
\end{tabular}

Another important aspect in the operation of gridconnected capacitor banks is the impact of the grid voltage distortion. Undesired current harmonic components flow though the capacitors due to the distortion, as the capacitor impedance decreases with higher frequency components.

The following scenarios are considered for study of the switching transients, and the corresponding simulated current waveforms are presented in Figure 13. In this case study, it is considered that the capacitors are initially discharged.

A) Without grid voltage distortion and optimum switching;

B) Without grid voltage distortion and non-optimum switching;

C) With grid voltage distortion and optimum switching;

D) With grid voltage distortion and non-optimum switching.
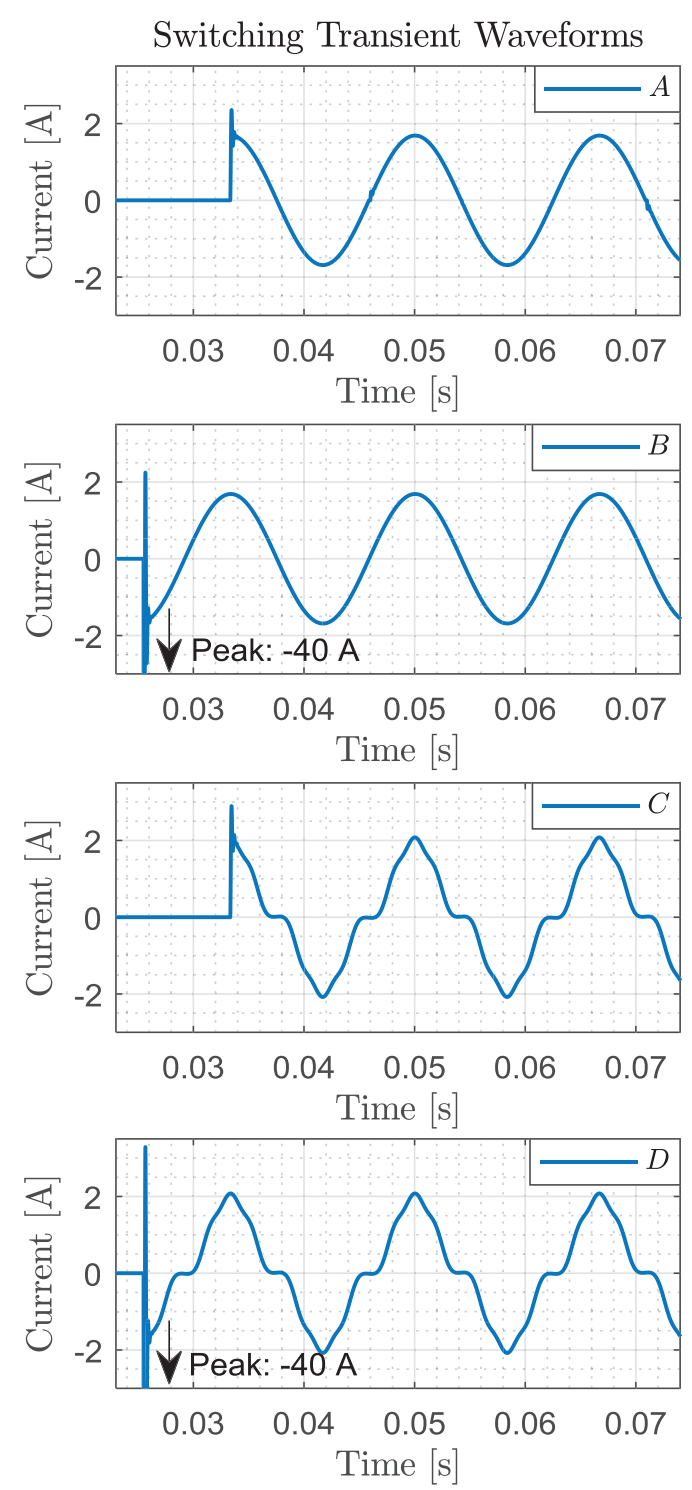

Fig. 13. Simulated current waveforms for capacitor bank switching for cases A, B, C and D.

In the simulations, the rms grid voltage fundamental frequency component is assumed to be of $127 \mathrm{~V}$.

Additionally, in order to consider the effect of the voltage distortion of the laboratory grid in case $\mathrm{C}$ and $\mathrm{D}$, harmonic components with distortion levels of $7.5 \%$ at the $3^{\text {rd }}$ order, 
$1.25 \%$ at the $5^{\text {th }}$ order and $0.63 \%$ at the $7^{\text {th }}$ order are added to the grid voltage.

The results demonstrate the impact of the grid voltage distortion on the obtained current waveform. They also emphasize the magnitude of the switching overcurrents that happen when operating the capacitor bank without measures to limit those transients [16].

It is possible to see that the transients are adequately limited by performing optimal switching, even in the presence of grid voltage harmonics. Null transient current is expected only when the grid is modelled as an ideal voltage source. For a real-world situation, a RLC damped oscillation appears. On the other hand, if non-optimal switching is expected to be performed, other measures (such as insertion of a series inductor [17] [20]) need to be taken in order to avoid damage to both the capacitor bank and the thyristors due to transient overcurrents.

The experimental setup used to validate the simulation results is depicted in Figure 14. Reactive power variation and study of the switching transients are performed in the singlephase configuration in this case study. The inductors are available for further studies on alternatives to mitigate the switching transients if necessary.

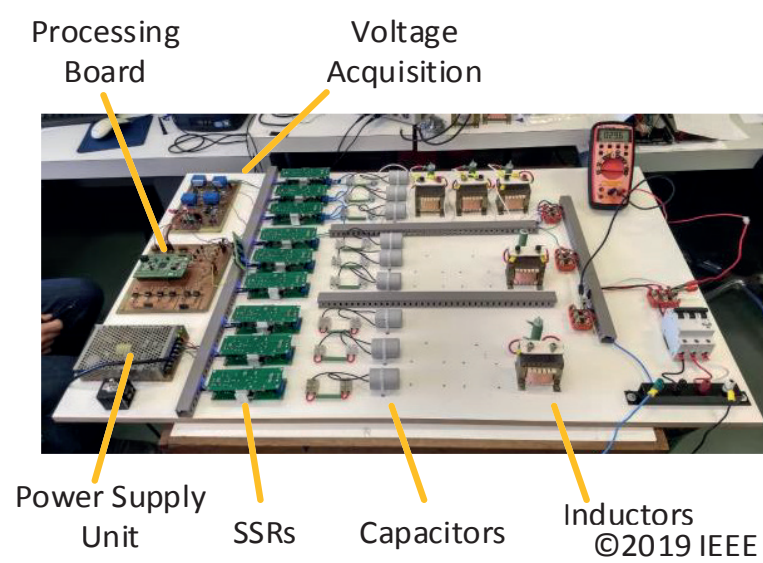

Fig. 14. Overview of the experimental platform.

In the simulations, the transient overcurrents reached up to 40 A peak in the $127 \mathrm{~V}$ grid. Those current levels would damage the platform. Therefore, using a variable transformer the grid voltage is reduced by 10 times, hence limiting those overcurrents.

The laboratory grid voltage is inherently distorted, which only allows examination of the cases $\mathrm{C}$ and $\mathrm{D}$. To obtain a pure sinusoidal voltage waveform for cases $\mathrm{A}$ and $\mathrm{B}$, more sophisticated laboratory equipment such as controlled AC sources are required, which are usually not found in didactic laboratories used in undergraduate courses.

For optimal switching with grid voltage distortion (case C) the waveforms of the filter current (in dark green), the grid voltage (in dark purple) and the switching command (in dark yellow) are shown in Figure 15. After the switching command is received, the control system waits until the grid voltage is equal to the capacitor voltage to start generating the gate signals.

In the case of non-optimal switching with grid voltage distortion (case D), the same waveforms are presented in Figure 16. The control system starts generating the gate pulses at an arbitrary instant. It is possible to see the significant transient overcurrent, which also generates a voltage dip.

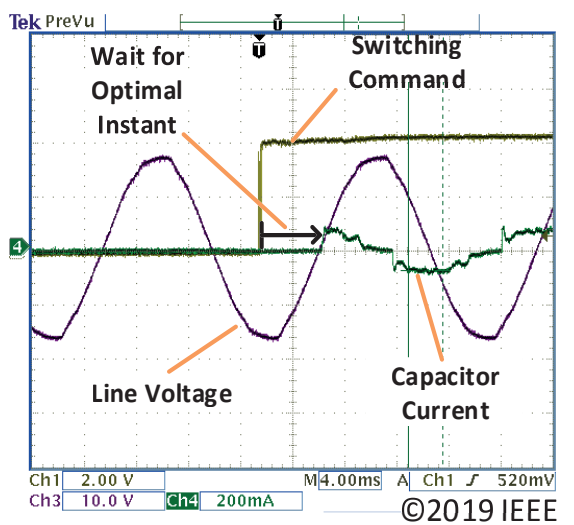

Fig. 15. Experimental waveforms for optimum switching with grid voltage distortion (case C).

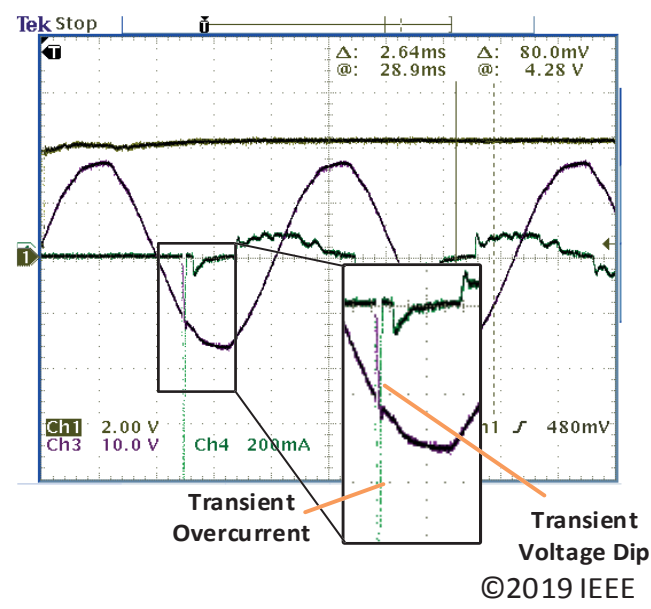

Fig. 16. Experimental waveforms for non-optimum switching with grid voltage distortion (case D).

Figure 17 provides a detailed view of the capacitor current waveform, right after the switching transient. It is possible to see the effect of the laboratory grid voltage distortion on the capacitor current (harmonics and spikes), mainly caused by equipment with single phase rectifiers using capacitive filter.

The spikes can be explained by the behavior of the grid voltage near its positive peak, where a sudden negative derivative can be seen, caused by the nearly simultaneous interruption of the current absorbed by the neighboring rectifiers. This causes the negative transient in the capacitor current every cycle, in steady-state operation. Similar behavior occurs in the negative cycle.

This analysis is out of the scope of this paper but gives some ideas for laboratory classes. The simulated waveforms shown in Figure 13 (cases C and D), in spite of showing the effect of grid distortion on the capacitor currents, are considerably different from the experimental ones (Figures 15-17). It is an opportunity to suggest students to improve the initial model by including more voltage harmonics and considering their individual phases in the simulations. 


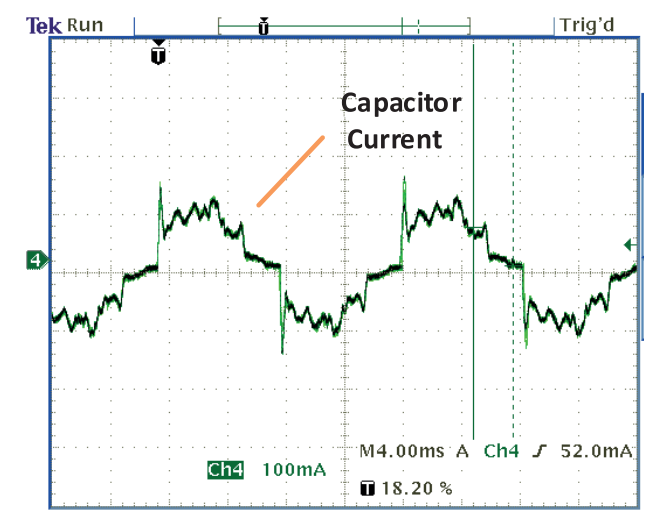

Fig. 17. Experimental waveform for the capacitor current in steadystate.

Finally, Figure 18 shows the current waveform obtained for three positive step variations of the reactive power in a single-phase system (Figure 11). For obtaining this waveform, optimum switching is performed.

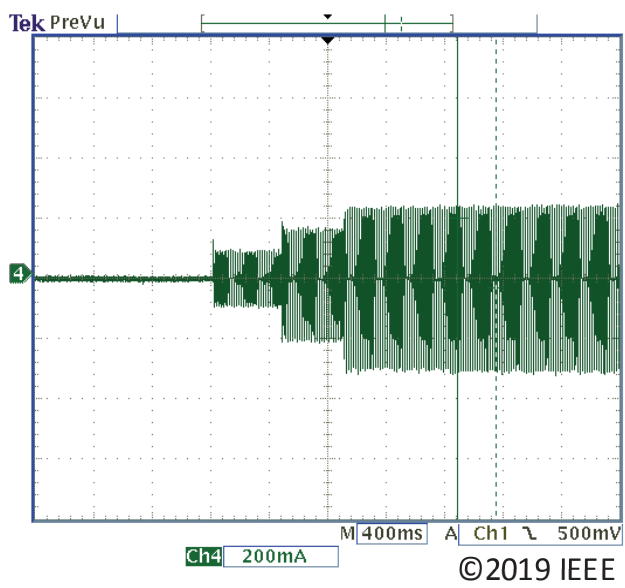

Fig. 18. Experimental current waveform for consecutive step variations of the reactive power.

The obtained results show that by using this didactic platform, it is possible to demonstrate several important aspects related to the operation of capacitor banks connected to the grid, such as the switching instant control, the resulting transients and the effect of the voltage distortion, which can lead to equipment damage or power quality problems. It is also a good opportunity to discuss modelling issues to predict the system behavior in digital simulations.

\section{Single-Phase Controlled Rectifier}

By using the phase-leg interconnection shown in Section III, it is possible to build the single-phase controlled rectifier shown in Figure 19. The grid voltage is represented by $v(t)$, the grid current by $i_{A C}(t)$, the load voltage by $v_{0}(t)$ and the load current by $i_{0}(t)$. The rectifier input voltage (after the grid reactance) is represented by $v_{A C}(t)$.

The circuit parameters are listed in Table II, where the values of the grid inductance $L_{S}$, of the grid resistance $R_{S}$, of the load inductance $L_{0}$ and of the load resistance $R_{0}$ are shown.

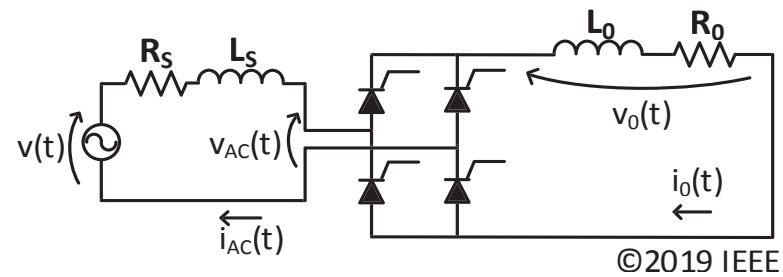

Fig. 19. Circuit diagram of the controlled rectifier.

TABLE II

Circuit Parameters

\begin{tabular}{cc}
\hline Parameter & Value \\
\hline$L_{S}$ & $50 \mu \mathrm{H}$ \\
\hline$V_{R M S}$ & $110 \mathrm{~V}$ \\
\hline$R_{S}$ & $0.5 \Omega$ \\
\hline$L_{0}$ & $500 \mathrm{mH}$ \\
\hline$R_{0}$ & $10 \Omega$ \\
\hline & (C) 2019 IEEE
\end{tabular}

Simulations of the controlled rectifier with a phase angle delay $\alpha$ of $60^{\circ}$ are performed using PSIM [21]. The resulting waveforms are presented in Figure 20.
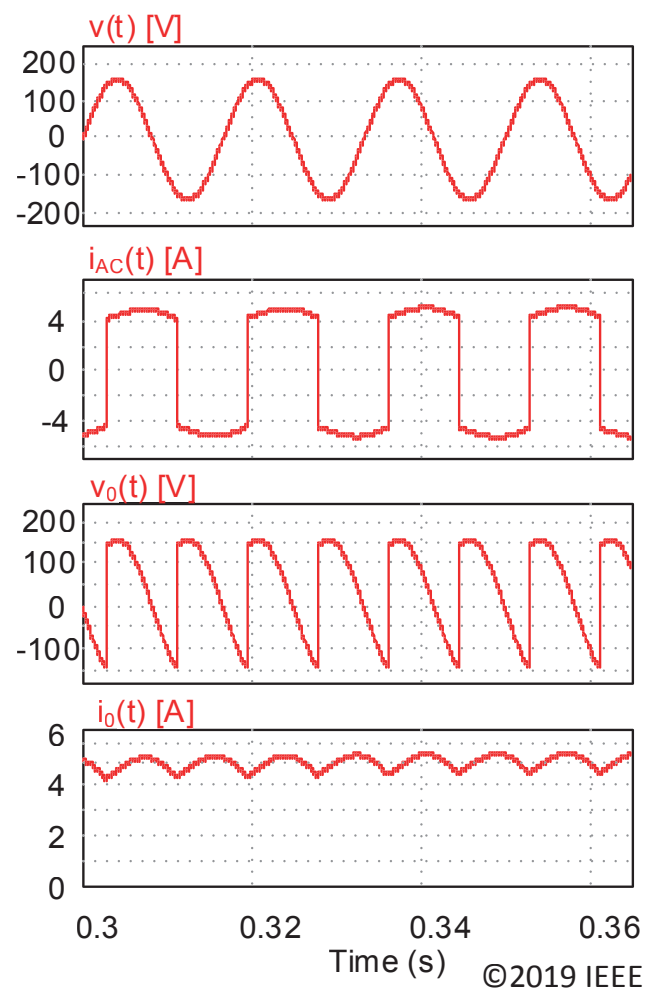

Fig. 20. Simulated waveforms of the single-phase controlled rectifier.

In the operation of the controlled rectifier, the average output voltage and current of the rectifier are calculated [21] as presented in (3).

$$
\overline{V_{0}}=\frac{2 \sqrt{2}}{\pi} V_{R M S} \cos \boldsymbol{\alpha}=49.5 \mathrm{~V} ; \overline{I_{0}}=\frac{\overline{V_{0}}}{R}=4.95 \mathrm{~A} .
$$

Experimental results are obtained using the setup shown in Figure 21 in order to validate the simulations. Four individual thyristor modules are used. 


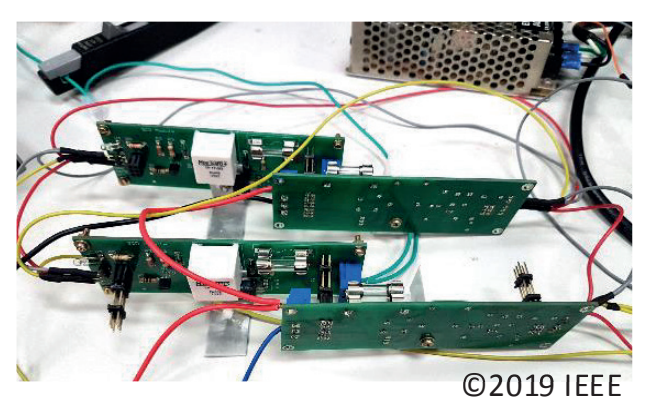

Fig. 21. Experimental setup of the single-phase controlled rectifier.

The experimental waveforms are obtained, and Figure 22 shows the rectifier input voltage and grid current waveforms (AC side) and Figure 23 shows the output voltage and current (DC side).

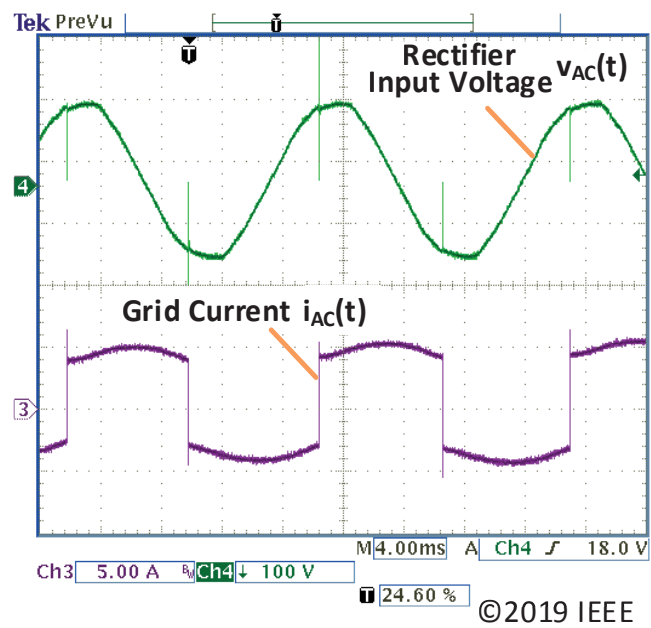

Fig. 22. Experimental rectifier input voltage and grid current waveforms.

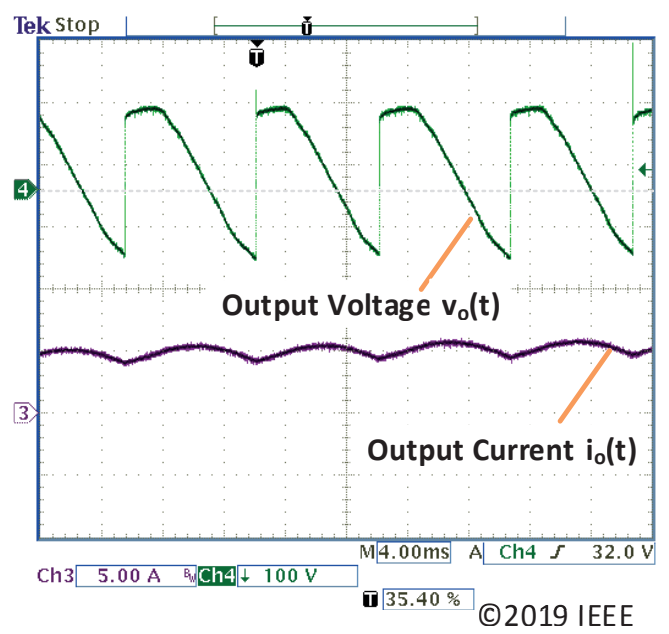

Fig. 23. Experimental output voltage and current waveforms.

The obtained results show good agreement with the simulations and the calculation in (3). In Figure 22, it is possible to recognize several spikes on the rectifier input voltage and current waveforms. Those are caused by the commutation of the thyristor valves. An example of a commutation event is illustrated in Figure 24, where the conducting valves are highlighted in black and blocking valves in white.

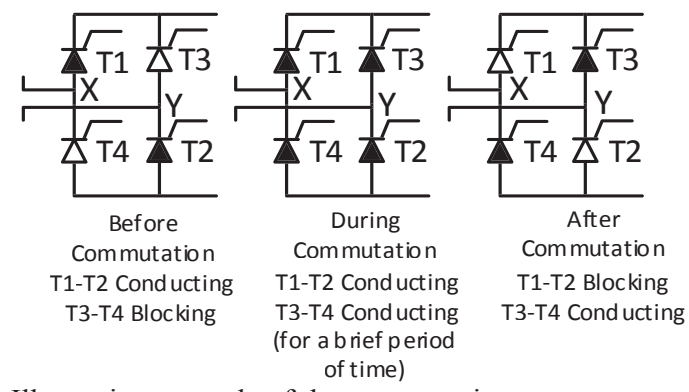

Fig. 24. Illustrative example of the commutation process.

Initially, T1-T2 are conducting and T3-T4 are blocking. At the phase angle delay $\alpha, \mathrm{T} 3-\mathrm{T} 4$ receive gate pulses and start conduction. The grid inductance $L_{S}$ (Figure 19) does not allow T1-T2 to stop conducting instantly. For a brief period of time, called commutation time $\mu$, all valves are conducting simultaneously. This causes a temporary AC short circuit between nodes $\mathrm{X}$ and $\mathrm{Y}$ on the circuit diagram, that can be visualized at the rectifier input voltage in Figure 22, whose duration depends on the grid inductance $L_{S}$ and the DC current amplitude. At the end of the commutation time, T1T2 enter into reverse recovery mode [19]. Therefore, the spikes in the rectifier input current and in rectifier input voltage waveform occur.

Those effects can be reduced by usage of appropriate snubbers [19] [23]. To keep the setup as simple as possible, the usage of snubbers is avoided, because the focus of this introductory experiment is to demonstrate the operation principles of the controlled rectifier. The project and use of snubber circuits could be done in more advanced courses.

The results show the usage of the didactic platform for demonstrating several aspects regarding line-commutated converters, such as the calculation and verification of the average output voltage and currents. It is also possible to study the commutation process with varying phase angle delay and the aspect of the resulting waveforms.

\section{CONCLUSIONS}

This paper extends the results originally presented in [8], where a didactic platform for studying power electronics circuits based on thyristor switches is introduced. The main advantage of this platform is its flexibility and modularity, which allows the study of different topologies.

Three interconnection possibilities are presented, namely the individual SCR, the SSR and the thyristor phase-leg. Examples of didactic applications are shown, including the characterization of the thyristor, the switched capacitor bank and a controlled rectifier.

The thyristor module is available online under an open hardware license in [24]. This allows interested students and/or laboratories to build a full experimental setup in a shorter time, without having to design a thyristor module from the beginning.

Additionally, the material cost for each thyristor module is reduced. At the time of submission of the article, it is of US\$8.75 including circuit board manufacturing. 


\section{ACKNOWLEDGEMENTS}

The authors would like to thank Texas Instruments, STMicroelectronics and TDK/EPCOS for their support. This work was financially supported by the Sao Paulo Research Foundation (FAPESP) research grants 2016/16542-5 and 2016/01930-0 and by the Brazilian National Council for Scientific and Technological Development $(\mathrm{CNPq})$ grants 306970/2015-5 and 311789/2014-5. This study was financed in part by the Coordination for the Improvement of Higher Education Personnel (CAPES) - Finance Code 001.

\section{REFERENCES}

[1] E. A. Vendrusculo, A. A. Ferreira, J. A. Pomilio, "Plataforma Didática Para Avaliação Rápida E Experimental De Estratégias De Controle Em Eletrônica De Potência", in Eletrônica de Potência - SOBRAEP, vol. 13, n², pp. 99-108, May 2008.

[2] L. G. Rolim, W. Suemitsu, R. M. Stephan, M. B. Medeiros, "An experimental setup for the study of oriented control of AC machines", in Anais do XVIII Congresso Brasileiro de Automática, vol. 01, pp. 10081011, Sep. 2000.

[3] M. V. Lazarini, E. Ruppert Filho, "Induction motor control didactic set-up using sensorless and sliding mode DTC strategy", in Eletrônica de Potência SOBRAEP, vol. 13, n 4, pp. 291-299, Nov. 2008.

[4] A. V. S. Andrade, R. M. Stephan, "Didactic System For Control Of Electrical Machines In Education And Research Laboratories", in Proc. of the 2019 IEEE 15th Brazilian Power Electronics Conference and 5th IEEE Southern Power Electronics Conference (COBEP/SPEC), vol. 01, pp. 943-948, Dec. 2019.

[5] J. L. da Silva Neto, L. G. Rolim, W. I. Suemitsu, L. O. A. P. Henriques, P. J. C. Branco and M. G. Simoes, "Application of learning methodologies in control of power electronics drives", in Proc. of the 2003 IEEE International Symposium on Industrial Electronics, vol. 01, pp. 358-363, June 2003.

[6] S. A. O. da Silva, D. H. Wollz, L. P. Sampaio, "Development of a didactic workbench using real-time monitoring system for teaching of photovoltaic systems", in Eletrônica de Potência - SOBRAEP, vol. 23, n³, pp. 371-381, Sep. 2018.

[7] M. R. S. Brito, F. C. Melo, L. C. Freitas, J. B. Vieira Jr., E. A. A. Coelho, V. J. Farias, L. C. G. Freitas, "Didactic Platform for Teaching of Three-Phase Rectifier Circuits in Power Electronics", in International Journal of Electrical Engineering \& Education, vol. 51, n ${ }^{\circ} 4$, pp. 279-291, Oct. 2014.

[8] Festo Didactic , "Thyristors and Power Control Circuits Module: Labvolt Series Datasheet”, 2019 [Online]. Disponível em: <www.labvolt.com>

[9] L. G. Rolim, R. M. Stephan, W. Suemitsu, "Power electronics teaching laboratory at UFRJ", in Proc. of COBEP, vol. 93, pp. 336-341, Nov./Dec. 1993.

[10]L. Koleff, L. Araújo, M. Zambon, W. Komatsu, E. Pellini, L Matakas, "Flexible Didactic Platform for Thyristor-Based Circuits", in Proc. of the 2019 IEEE 15th Brazilian Power Electronics Conference and 5th IEEE Southern Power Electronics Conference (COBEP/SPEC), vol. 01, pp. 410-415, Dec. 2019.

[11]Power Innovations, "Silicon Controlled Rectifiers TIC126 Series Datasheet”, 1997 [Online]. Disponível em: <www.farnell.com>

[12]IPC Generic Standard on Printed Board Design, IPC2221, 1998.

[13] Miniature fuses - Part 2: Cartridge fuse-links, IEC Std. 60127-2, 2014.

[14]W. Komatsu. Power Electronics. Lecture Notes, Polytechnic School of the University of São Paulo, São Paulo, Brazil, 2016.

[15]Minitrafo, "Pulse transformer specification", 2019. [Online]. Disponível em: <www.minitrafos.com.br $>$

[16]R. M. Mathur and R. K. Varma, Thyristor-based FACTS controllers for electrical transmission systems, WileyInterscience, $1^{\text {a }}$ Edição, New York, 2002.

[17]N. G. Hingorani and L. Gyugyi, Understanding FACTS: concepts and technology of flexible $A C$ transmission systems, Institute of Electrical and Electronics Engineers, $1^{\text {a }}$ Edição, New York, 2000.

[18]M. H. Rashid, Power electronics handbook: devices, circuits and applications, Academic Press, 2a Edição, Cambridge, 2010.

[19]N. Mohan, T. M. Undeland, W. P. Robbins, Power electronics: converters, applications, and design, John Wiley \& Sons, $3^{\text {a }}$ Edição, New York, 2003.

[20]L. Araújo, M. Zambon. Static reactive power generation with capacitor switching - Gerador de reativos estático com chaveamento de capacitores. Undergraduate Thesis, Polytechnic School of the University of São Paulo, São Paulo, Brazil, 2018.

[21]Powersim Inc., "PSIM v9.1 User's Guide", 2011. [Online]. Disponível em: <www.powersimtech.com>

[22]J. Specovius, Grundkurs Leistungselektronik Bauelemente, Schaltungen und Systeme - A First Course on Power Electronics Components, Circuits and Systems, Vieweg Teubner, 9a Edição, Wiesbaden, 2011.

[23]W. McMurray, "Optimum Snubbers for Power Semiconductors", in IEEE Transactions on Industry Applications, vol. IA-8, n 5, pp. 593-600, Sep. 1972.

[24]LEP-PEA-EPUSP, "Open Source Power Electronics", 2019. [Online]. Disponível em: <www.github.com/LEPPEA-EPUSP>

\section{BIOGRAPHIES}

Lucas Koleff, born in São Paulo, Brazil in 1991, received his B.Sc. degree with honors from the University of São Paulo (USP), Brazil and his D.D. M.Sc. degree from the Technical University of Darmstadt (TUD), Germany in 2015. Between 2012 and 2013 he was an undergraduate research assistant at the Group of Machines and Drives from the USP and between 2014 and 2015 he was a research assistant at the Institute for Power Electronics and Drives from the TUD. Since 2016 he has been doing research at the Power Electronics Laboratory from the USP with a direct doctorate scholarship from the São Paulo Research Foundation. He is currently a member of the IEEE Power Electronics and 
Industry Applications Societies and has served as a reviewer for several IEEE sponsored conferences. He has published more than 10 articles in national and international conferences and journals. His current research interests are power converters modelling and control, modern and robust control techniques and electromagnetic compatibility applied to power electronics. He has also received the "Áurio Falcone" prize from the USP, Brazil in 2015 and the APEC Outstanding Poster Presentation Award from the IEEE in 2017.

Lucas Araújo, born in São Paulo, Brazil in 1994, received his B.Sc. degree from University of São Paulo (USP), Brazil in 2018. In 2015 he was an undergraduate research assistant at the Center for Studies in Regulation and Power Quality at the USP. In 2016, he was in the Karlsruhe Institute of Technology (KIT), Germany with a Science without Borders scholarship. He received the "Honorable Mention" prize from the Energy and Automation Department at the USP in 2018. Currently, he is pursuing this M.Sc. degree in renewable energies at the USP, Brazil.

Mário Zambon, born in São Paulo, Brazil in 1993, received his B.Sc. degree from University of São Paulo, Brazil in 2018. He received the "Honorable Mention" prize from the Energy and Automation Department from the University of São Paulo in 2018.

Wilson Komatsu, born in São Paulo, Brazil in 1963, received the B.S., M.S., and Ph.D. degrees in Electrical Engineering from the Polytechnic School of the University of São Paulo (EPUSP), São Paulo, in 1986, 1992, and 2000, respectively. From 1987 to 1989, he was a Development Engineer with the Foundation of Engineering and
Technology, University of São Paulo, São Paulo. In 1989, he joined EPUSP, where he is currently an Associate Professor of power electronics. His research areas are control and modeling of static converters and their application to electrical power systems and electrical power quality. Prof. Komatsu is a member of the Brazilian Power Electronics Society (SOBRAEP).

Eduardo Pellini, born in São Paulo, Brazil in 1975. He received the B.Sc., M.Sc., and Ph.D. degrees from University of São Paulo, São Paulo, Brazil, in 2000, 2005, and 2010, respectively. He joined the University of São Paulo, São Paulo, Brazil, in 2011, where he is presently an Assistant Professor with the Electric Energy and Automation Engineering Department. His research fields are power systems control, protection and automation.

Lourenco Matakas Junior, born in São Paulo, Brazil, received the B.S., M.S., and Ph.D. degrees in electrical engineering from the Polytechnic School of the University of São Paulo (EPUSP), São Paulo, Brazil, in 1984, 1989, and 1998, respectively. From 1984 to 1989, he was a Development Engineer with the Foundation of Engineering and Technology, University of São Paulo. From 1993 to 1995 he was a Research Assistant at the Department of Electrical Engineering of The University of Tokyo, Japan. In 1996 he joined the Pontifical Catholic University of São Paulo, leaving in 2011 as an Associate Professor. In 1996, he joined the EPUSP, where he is currently an Associate Professor in the Power Electronics. His research focus on the control of static converters connected to the grid, PLLs and PWM strategies. 